\title{
ALTAS HABILIDADES/SUPERDOTAÇÃO: A CRIATIVIDADE COMO UM DE SEUS TRAÇOS DETERMINANTES
}

\author{
Mariana Patricia Soares de Oliveira ${ }^{1}$ \\ Bárbara Amaral Martins ${ }^{2}$
}

\begin{abstract}
Resumo: $\mathrm{O}$ fenômeno altas habilidades/superdotação (AH/SD) é comumente associado à capacidade cognitiva, mas apesar de não se restringir às habilidades acadêmicas, é determinado pela interaçáo de três traços: habilidade a acima da média, comprometimento com a tarefa e criatividade. Este estudo foi realizado em uma escola pública localizada no interior do estado de Mato Grosso do Sul e teve como objetivo conhecer as práticas educacionais voltadas para o desenvolvimento do potencial criativo, bem como as concepçóes de criatividade e AH/SD presentes no fazer docente. Os dados foram coletados por meio de observaçóes em uma sala de aula do $1^{\circ}$ ano do Ensino Fundamental e entrevista com a professora regente. Após as transcriçôes, a análise do material coletado ocorreu qualitativamente por meio da técnica de Análise de Conteúdo. Os resultados demonstraram que é necessário investir na formação de professores em relação a esse campo levando em consideração a presença de concepçóes equivocadas e ausência de práticas de incentivo à criatividade. Assim, destacase a relevância da promoção de uma prática docente que desenvolva as potencialidades criativas de cada sujeito, concebendo a criatividade como um componente determinante das AH/SD.
\end{abstract}

Palavras-chave: Criatividade; Práticas educacionais; Altas habilidades/superdotação.

\section{HIGH ABILITIES OR GIFTEDNESS: CREATIVITY AS ONE OF ITS DETERMINANTS}

\begin{abstract}
The high abilities or giftedness phenomenon is commonly associated with cognitive ability, but although it is not restricted to academic abilities, it is determined by the three traits interaction: above-average ability, commitment to the task, and creativity. This study was carried out in a public school located in the interior of the state of Mato Grosso do Sul and had as objective to know educational practices aimed at the development of creative potential, as well as the conceptions of
\end{abstract}

1 Graduada em Pedagogia pela Universidade Federal de Mato Grosso do Sul, Campus do Pantanal, Corumbá, MS.

2 Docente do curso de Pedagogia, da Universidade Federal de Mato Grosso do Sul, Campus do Pantanal, especialista em Psicopedagogia com Mestrado em Educação e Doutora em Educação pela Universidade Estadual Paulista "Júlio de Mesquita Filho", Campus de Marília, SP. 
creativity and high abilities or giftedness present in the teaching practice. The data were collected through observations in a classroom of the 1st year of elementary school and interview with the regent teacher. After the transcriptions, the analysis of the collected material occurred qualitatively through the technique of Content Analysis. The results showed that it is necessary to invest in the training of teachers in this field taking into account the presence of misconceptions and lack of practices to encourage creativity. Thus, the relevance of the promotion of a teaching practice that develops the creative potential of each subject is highlighted, conceiving creativity as a determining component of high abilities or giftedness.

Keywords: Creativity; Educational practices; High abilities; Giftedness.

\section{Introduçáo}

Considerado um dos principais teóricos que tratam das altas habilidades/ superdotação (AH/SD), Renzulli (2004) discorre que a literatura sobre superdotados e talentosos apresenta a existência de duas finalidades geralmente aceitas para oferecer Educação Especial para os jovens com elevado potencial. A primeira finalidade é proporcionar-lhes oportunidades para um maior crescimento cognitivo e autorrealização. A segunda finalidade é expandir a quantidade de pessoas que serão capazes de contribuir na resolução dos problemas da sociedade contemporânea, tornando-se autores de novos conhecimentos e manifestações artísticas.

Devido à realização de várias pesquisas neste campo, Renzulli (2004) conceituou as altas habilidades/superdotação com base na interação destes elementos: a) habilidade acima da média, b) envolvimento com a tarefa e c) criatividade, que, atualmente são conhecidos como os Três Anéis.

A habilidade acima da média pode se apresentar de duas maneiras: habilidades gerais e habilidades específicas. Consideram-se habilidades gerais características que se aplicam em todos os domínios ou em domínios mais amplos, resultando na capacidade de processamento de informações e adaptação a novas experiências (RENZULLI, 2005; VIRGOLIM, 2010).

Para Virgolim (2010), as habilidades específicas dizem respeito aos indivíduos que adquirem habilidade de um determinado conhecimento ou área de domínio para desempenhar uma ou mais atividades especializadas, separadas ou em conjunto.

Virgolim (2010) ressalta que, para Renzulli, ambos os conceitos devem ser compreendidos como resultado de um domínio superior do potencial em uma determinada área específica. Sendo assim, este termo diz respeito a " [...] pessoas que possuem a capacidade já desenvolvida ou o potencial para desenvolver habilidades em uma determinada área do desenvolvimento." (VIRGOLIM, 2010, p.4).

Considera-se envolvimento com a tarefa, segundo Renzulli (2005), a energia produzida durante a resolução de um problema particular ou em uma área específica de desempenho, onde o indivíduo trabalha arduamente, por um longo período de tempo, com confiança e dedicação em sua tarefa. 
Em relação à criatividade, Neves-Pereira (2007, p. 15) apresenta a criatividade "como um recurso humano, como uma função psicológica que todos nós possuímos". A criatividade se apresenta de diversas maneiras e seu desenvolvimento pode ser influenciado pelas condições do ambiente onde o indivíduo está inserido. Todos nós possuímos traços de criatividade, porém eles se manifestam de maneiras diferentes em cada indivíduo (NAKANO; WESCHSLER, 2007; MARTINS; CHACON, 2016a).

Salientamos que, entre os três elementos que compõem as AH/SD, esta pesquisa irá se pautar na investigação da criatividade como um de seus fatores determinantes.

Outro conceito relevante para esta pesquisa é o de precocidade. Para Martins (2015), a precocidade é “[...] compreendida como antecipação no desenvolvimento da criança dentro de um determinado campo ou área de domínio" (MARTINS; CHACON, 2016a, p. 97), de maneira que o indivíduo que se encontra em um grupo específico, terá certas habilidades avançadas em relação ao seu grupo de pertencimento.

A autora esclarece que a precocidade pode ser passageira, deixando de ser apresentada na medida em que o desenvolvimento infantil se completa, mas adverte que, em certos casos, essa precocidade pode representar um indicador de superdotação. Logo, é imprescindível o reconhecimento da aprendizagem precoce e a organização de um ambiente educativo que reconheça e desenvolva suas potencialidades.

\section{Contexto Histórico do estudo das Altas habilidades/Superdotaçáo}

Voltando o nosso olhar para tempos remotos, pesquisando sobre o reconhecimento dos superdotados ao longo da história que se inicia anteriormente à Era Cristã, encontramos os primeiros registros da educação de superdotados na Antiguidade Clássica. Gama (2006) relata que o início da atenção ao talento data da Grécia Antiga: discorre que a Academia de Platão selecionava moças e rapazes pela inteligência e desempenho físico, independentemente da classe social, e o ensino na Academia era gratuito para aqueles que possuíam talentos ou aptidões. Já em Roma a educação superior era destinada apenas aos mais capazes intelectualmente. $\mathrm{Na}$ China, desde o século VII, considerava-se que a criança talentosa não se desenvolvia sem educação apropriada. No Japão, a partir do século XVII, somente as crianças oriundas de famílias com maior poder aquisitivo recebiam educação especial, fato que nos permite observar a mudança na compreensão dos cidadãos mais capazes no decorrer da história, visto que o foco se distancia dos interesses sociais e recai sobre os interesses individuais e hegemônicos.

Gama (2006) relata que, na Europa do século XX, os primeiros textos sobre superdotação e talento são datados de 1910, os quais foram publicados na Iugoslávia. Cupertino (2008) afirma que a primeira escola para alunos com inteligência superior surgiu na Holanda no ano de 1921 e, na Alemanha, William Stern formulou e introduziu o "conceito de quociente de inteligência" (QI). Galton, 
na Inglaterra, realizou a primeira pesquisa para testar a inteligência. Porém, nos anos de 1960, o movimento de igualdade de direitos gerou a descrença em testes de aptidão, e numa educação especializada para os considerados superdotados, pois a diferenciação passou a ser compreendida como elitismo.

Segundo Cupertino (2008), a partir dos anos 1970, houve um crescente investimento no potencial humano por parte de determinados países da Ásia, que passaram a valorizar cada vez mais o desenvolvimento da educação para os talentos e altas habilidades, sendo hoje, um continente onde há significativa preocupação com o estímulo das potencialidades humanas.

Cupertino (2008) relata que nos Estados Unidos, o processo de atenção às altas habilidades além de ter sido vagaroso, era exceção no século XIX. Afirma que a primeira medida pedagógica nesta área só foi adotada em 1862, permitindo aos alunos superdotados a aceleração da aprendizagem, ou seja, desenvolveu-se, mais precisamente, por causa da Guerra Fria, momento em que Louis Terman começou a medir o Q.I com o teste Stanford-Binet, e Leta Hollingworth, defendia a educação diferenciada para os altamente habilidosos. É importante destacar que, em 1957, com o lançamento do foguete Sputnik pela União Soviética, o avanço tecnológico evidenciado fez com que o governo americano se sentisse ameaçado. Em resposta, passou a financiar pesquisas que visam à identificação e ao incentivo de talentos nas áreas de interesse nacional (RENZULLI, 2004). Na sequência, os anos de 1960 e 1970 trouxeram a decadência dos programas destinados aos estudantes mais capazes em razão da centralização da opinião pública na igualdade de direitos, porém, o interesse na educação dessas pessoas não se extinguiu por completo, pois era entendida como uma maneira de garantir a liderança e a soberania nacional (GAMA, 2006).

\section{As altas habilidades/superdotaçáo no Brasil}

Cupertino (2008) relata que diferentemente da maioria dos países do mundo, no Brasil, as AH/SD tendem a ser ignoradas no contexto educacional. Por isso, ressalta que a superdotação precisa ser estudada e reconhecida em todos os seus aspectos, oferecendo-se ao indivíduo condições educacionais adequadas ao seu potencial (CUPERTINO,1998). Porém, na realidade, não é o que acontece. O Sistema educacional do Brasil não considera relevante o atendimento educacional adequado a quem já foi privilegiado com alguma habilidade ou inteligência acima da média. O que leva a pensar que os alunos com AH/SD estão esquecidos nas salas de aula, e os seus talentos se tornam invisíveis.

Sobre o desenvolvimento da atenção às AH/SD no Brasil, Ferrer (s/d), Gama (2006) e Delou (2007) nos contam que o marco inicial ocorreu nos anos de 1930, quando Leoni Kaseff publicou "A Educação dos Supernormais". Gama (2006) apresenta que, antes da publicação do referido livro, Ulisses Pernambuco, em 1924, propôs o início do trabalho direcionado ao indivíduo considerado superdotado, onde o mesmo seria identificado por meio de um teste que era utilizado pelo exército americano na Primeira Guerra Mundial. 
Antipoff e Campos (2010) relatam que no Brasil, a preocupação com os "bem-dotados"3 teve início em 1929, quando Helena Antipoff buscava sensibilizar a todos para a necessidade de olharmos atentamente para eles, propondo alternativas que pudessem favorecer o desenvolvimento pleno desses indivíduos. Relatam-nos que a primeira forma de atendimento educacional especializado aos bem-dotados teve origem em 1945, sendo criado por Helena Antipoff, na Sociedade Pestalozzi do Rio de Janeiro. Porém, apenas no ano de 1971, quando aconteceu o I Seminário sobre Superdotação do país, em Brasília, apareceu, pela primeira vez, a menção ao superdotado na Lei de Diretrizes e Bases da Educação Nacional, ressaltando a necessidade dos mesmos receberem um atendimento diferenciado.

No que tange ao capítulo V, art. 58 da Lei de Diretrizes e Bases da Educação Nacional (LDBEN) no 9394/96, considera-se a "educação especial à modalidade de educação escolar, oferecida preferencialmente na rede regular de ensino, para educandos com deficiência, transtornos globais do desenvolvimento e altas habilidades ou superdotação" (BRASIL, 2013, p. 33).

A LDBEN no 9394/96, afirma que os sistemas de ensino deverão assegurar aos educandos com necessidades especiais, dentre outros direitos, professores com especialização adequada, para atendimento especializado, além de professores do ensino regular devidamente capacitados para a integração desses educandos nas classes comuns.

Em relação à Política Nacional de Educação Especial na Perspectiva da Educação Inclusiva (BRASIL, 2008, p. 9) consideram-se alunos

[...] com altas habilidades/superdotação aqueles que demonstram potencial elevado em qualquer uma das seguintes áreas, isoladas ou combinadas: intelectual, acadêmica, liderança, psicomotricidade e artes, além de apresentar grande criatividade, envolvimento na aprendizagem e realização de tarefas em áreas de seu interesse.

Sendo assim, aqueles que apresentam, em algumas dessas áreas, ou em conjunto, uma capacidade diferenciada quanto ao desenvolvimento destas peculiaridades do ser humano, requerem atenção e educação de qualidade, que promova o aprimoramento integral de suas habilidades.

\section{A criatividade}

Segundo Renzulli (2004), a superdotação está dividida em dois tipos, a superdotação escolar ou acadêmica e a superdotação produtivo-criativa. Ressalta que é preciso entender que existe uma diferença entre estas duas concepções e, é preciso que ocorram investimentos e interação entre ambas. $\mathrm{O}$ autor considera que a superdotação acadêmica geralmente acaba sendo mensurada por testes padronizados, que buscam encontrar indivíduos com capacidades cognitivas elevadas, mas, que deixam as habilidades criativas de lado.

3 Termo cunhado por Helena Antipoff para se referir a indivíduos com capacidades elevadas. 
Renzulli (2004) concebe a superdotação produtivo-criativa como aquela que

[...] descreve aqueles aspectos da atividade e do envolvimento humanos nos quais se incentiva o desenvolvimento de ideias, produtos, expressões artísticas originais e áreas do conhecimento que são propositalmente concebidas para ter um impacto sobre uma ou mais platéias-alvo (target audiences). As situações de aprendizagem concebidas para promover a superdotação produtivocriativa enfatizam o uso e a aplicação do conhecimento e dos processos de pensamento de uma forma integrada, indutiva e orientada para um problema real (RENZULLI, 2004, p. 83).

Wechsler e Nakano (2011) apresentam a criatividade como um campo multidimensional onde as características cognitivas e da personalidade, estão ligadas e interagem com os aspectos familiares e educacionais, dando origem a maneiras de pensar e criar, ou seja, por ser um campo diversificado, acredita-se que a criatividade está no plural, pois pode ser produzida e encontrada em diversos modos de criação (WECHSLER; NAKANO, 2011, p. 11).

Segundo Torrance (1976), o pensamento criativo é concebido como um caminho, onde o sujeito percebe atentamente elementos desconcertantes e busca ideias e maneiras capazes de modificar e/ou reestruturar o que for preciso, construindo novos resultados. Esse é o exercício da sua capacidade criadora.

Alencar, Braga e Marinho (2016) afirmam que é necessário que se prepare o aluno para resolver os problemas que a humanidade ainda enfrentará, por isso é imprescindível o estímulo à criatividade. Desse modo, cabe à escola valorizar, despertar e dar espaço à imaginação criadora, pois todos os seres humanos possuem um potencial criativo.

Assim, salienta-se a importância que a educação no Brasil volte mais atentamente o seu olhar para todos os alunos de nossas escolas, levando em consideração que todo indivíduo ali presente possui uma singularidade criativa, que precisa ser vista, desenvolvida e valorizada.

Rogers (1959 apud ALENCAR; BRAGA; MARINHO, 2016, p.17) ressaltava:

Eu insisto que há uma necessidade social desesperada de comportamentos criativos por parte dos indivíduos... Em um tempo em que o conhecimento, construtivo e destrutivo, está avançando de uma forma acelerada em direção a uma era atômica fantástica, uma adaptação genuinamente criativa parece se apresentar como a única possibilidade para o homem manter-se à altura das mudanças caleidoscópicas de seu mundo.

É preciso que a sociedade invista na educação, desenvolvendo práticas que despertem o potencial criativo de cada indivíduo, pois o mundo precisa de sujeitos capazes de acompanhar suas constantes mudanças.

Considerando a necessidade de estímulo à criatividade, este artigo teve como objetivo geral conhecer as práticas pedagógicas voltadas para o desenvolvimento da criatividade de alunos com $\mathrm{AH} / \mathrm{SD}$, propondo especificamente identificar as metodologias aplicadas em uma sala de aula de $1^{\circ}$ ano do Ensino Fundamental, bem como relatar e analisar as atividades educacionais voltadas ao desenvolvimento 
do potencial criativo e identificar as concepções da professora regente a respeito do desenvolvimento da criatividade.

\section{Procedimentos Metodológicos}

O presente trabalho teve como procedimento metodológico a abordagem qualitativa, pois pretendia verificar a relação da realidade do contexto educacional de uma sala de aula com o objeto de estudo. No que tange à pesquisa qualitativa, Gil (2008) explica que é aquela que possui como fonte de informações a realidade, onde o pesquisador é o principal instrumento.

A pesquisa qualitativa se caracteriza por ser capaz de apresentar a complexidade dos problemas pertinentes ao objeto de estudo, sendo possível compreender as particularidades e mudanças nos indivíduos. (DIEHL, 2004, DALFOVO; LANA; SILVEIRA 2008). Assim, nesse trabalho pretendeu-se conhecer e compreender profundamente as particularidades do objeto de estudo, sendo capaz de contribuir e influenciar em novas mudanças e pesquisas nessa área.

Para a sua construção, utilizou-se pesquisas, estudos bibliográficos e documentos legais, sendo este um estudo de caso caracterizado como exploratório e descritivo. Segundo Gil (2008) a pesquisa exploratória tem o objetivo de proporcionar uma visão geral sobre o tema. Já o estudo de caso é empregado para que se compreenda um fenômeno social em profundidade, considerando-se suas particularidades e seu contexto, à guisa de encontrar as ações mais adequadas à realidade investigada (CARVALHO, 2014).

Essa pesquisa foi realizada em uma escola pública estadual localizada em uma cidade do interior de Mato Grosso do Sul. Tivemos como participantes um aluno precoce com indicadores de $\mathrm{AH} / \mathrm{SD}$ e sua professora.

Em relação ao trabalho pedagógico e o desempenho do aluno com indicadores de AH/SD, foi feita uma observação não participante com o objetivo de conhecer as práticas pedagógicas voltadas para o desenvolvimento da criatividade do aluno observado e relatar as atividades educacionais que estão sendo trabalhadas com o mesmo. Segundo Gil (2008), nessa modalidade de observação, o pesquisador é apenas o espectador do grupo que está observando. O tempo de observação na sala de aula durou o período de um mês, com aproximadamente quatro horas diárias de permanência na turma, apenas no período matutino, sendo que as aulas observadas foram: português, matemática, educação física, artes, ciências e história. Os dados coletados foram registrados de modo manuscrito em Diário de Campo, e na sequência, digitados no programa de edição de textos word para posterior análise.

Também foi realizada uma intervenção com os alunos desta turma destinada à proposição de uma atividade de enriquecimento curricular com vistas à identificação das concepções da professora regente acerca da criatividade.

O enriquecimento curricular é uma forma de oferecer experiências diversificadas das proporcionadas pelo currículo regular, pode envolver adaptações curriculares, sendo que determinados conteúdos podem ser trabalhados de maneira 
mais abrangente, respeitando o tempo de escolarização (CUPERTINO, 2008). Neste estudo, o enriquecimento ocorreu através de uma atividade de intervenção que estimulasse os alunos a pensar e a se expressar. Optou-se pela contação de uma história, contendo alguns cartões em que cada um deles apresentava uma imagem de objetos, animais, personagens de histórias ou brinquedos. Na sala, foi entregue um cartão para cada criança e de acordo com o que havia em seus cartões, cada uma daria uma função para o que aparecia dentro da história.

A atividade ocorreu da seguinte maneira: a pesquisadora e uma das auxiliares foram caracterizadas de Fada Madrinha e Cinderela. Embora fossem personagens de uma mesma história, a ideia era fazer com que os alunos se sentissem dentro da história. A contação não seguiu a ordem presente na literatura, mas foi iniciada com base nos cartões retirados pelas personagens, a título de exemplificação de como seria a atividade.

Em seguida foram para o fundo da sala, onde todos se sentaram em círculo. Cada uma das crianças pegou um cartãozinho contendo uma imagem, com a qual teria que dar continuidade à história, de acordo com a imagem que retiravam da caixa.

Essa intervenção teve duração de aproximadamente uma hora, precedida da assinatura do Termo de Consentimento Livre e Esclarecido (TCLE) pelos responsáveis dos alunos, sendo registrada em vídeo com a colaboração de duas auxiliares de pesquisa.

As filmagens foram transcritas a partir da descrição das atividades, a participação dos alunos, o comportamento do aluno precoce e suas interações com os colegas, a professora e a pesquisadora.

Por fim, realizamos com a professora regente, um diálogo que se utilizou do recurso da entrevista, mediante assinatura do TCLE, para identificação de suas concepções em relação ao trabalho com práticas relevantes para o desenvolvimento do potencial criativo de todos os estudantes e, em especial, do aluno precoce com indicadores de $\mathrm{AH} / \mathrm{SD}$.

Considera-se a entrevista como uma importante técnica de investigação. Conforme afirma Gil (2008), a entrevista é um instrumento de interação social, ou seja, através de seu uso se estabelece um diálogo entre entrevistador e entrevistado, que interagem sobre um determinado tema ou situação. Salientamos que o tipo de entrevista que foi realizada é a entrevista por pautas, pois, segundo Gil (2008), esta apresenta certo grau de estruturação, ou seja, foram estabelecidos alguns pontos de interesse que nortearam o diálogo, tais como: concepção de criança; concepção de altas habilidades/superdotação; potencial criativo. A entrevista realizada com a professora regente durou aproximadamente 30 minutos, sendo a entrevista registrada integralmente por meio de registro escrito. 


\section{Caracterizaçáo dos participantes}

O menino observado, que daremos o nome fictício de Lucas, possuía seis anos de idade e estava cursando o primeiro ano do Ensino Fundamental na época do estudo. Durante uma pesquisa preliminar este foi identificado como um aluno precoce com indicadores de $\mathrm{AH} / \mathrm{SD}$, apresentando $92,3 \%$ de acertos em seu repertório básico de alfabetização, com um QI considerado muito superior no teste de inteligência R2.

A professora regente possui magistério e leciona há cerca de 30 anos, desde o ano de 1986, sendo efetivada pelo município desde 1998.

\section{Análise dos dados}

Os dados coletados por meio de observações e registrados no Diário de Campo, as transcrição das filmagens e da entrevista foram analisados qualitativamente, com base no referencial de Bardin (2016), que sugere que a análise de conteúdo seja escrita em três momentos: pré-análise; exploração do material; tratamento dos resultados, inferência e interpretação.

Primeiramente, escolhe-se o material a ser analisado, que, em nosso caso, se deu a priori. A leitura fluente dos documentos permite que surjam impressões, hipóteses e objetivos. Nesse momento, ocorre a escolha dos temas e constroem-se os indicadores em que serão organizados. O procedimento eleito foi o recorte do texto em unidades, com vistas à categorização, a qual foi sistematizada em quadros de registro.

\section{Resultados}

A seguir serão apresentados os dados obtidos durante a pesquisa por meio de observações, entrevista e intervenção, os quais foram analisados e categorizados em: a) aspectos comportamentais do aluno com indicadores de altas habilidades/ superdotação; b) enriquecimento curricular; c) concepções teóricas da professora e d) práticas pedagógicas.

\section{a) Aspectos comportamentais do aluno com indicadores de altas habilidades/ superdotação}

Durante o tempo de acompanhamento em sala de aula, Lucas apresentouse como um aluno dedicado, atencioso, participativo, com um forte traço de curiosidade e senso de humor, desempenhando as atividades que lhe eram propostas, sempre com muita energia. É importante ressaltar que o mesmo apresentou certa dificuldade na disciplina de matemática, no que tange às atividades de raciocínio lógico, mas, quando a professora levava para a aula jogos como recurso didático, ele se mostrava bem participativo e envolvido, principalmente nos jogos de quebracabeça. 
Em relação às atividades de escrita e leitura, Lucas realizava-as com facilidade. Possuía uma escrita bem desenvolvida, utilizando-se bastante da letra cursiva. Quando a professora levava músicas ou poesias para ler e trabalhar com os alunos, a oralidade e a escrita, percebemos que, na hora de cantar ele se envolvia mais rápido com a melodia do que os seus colegas demonstrando suavidade e segurança. Quando algum aluno apresentava dificuldade na leitura de alguma palavra, ele se apressava logo em dizer o que estava escrito.

Tivemos a oportunidade de assistir algumas a aulas de educação física, onde o professor trabalhava de forma dinâmica com os alunos. Durante as aulas o menino extravasava sua energia, desenvolvia todas as atividades e brincadeiras, percebemos que gostava muito de correr e jogar bola. Uma vez perguntamos se ele gostava de esportes:

“- Sim professora, gosto sim. Eu faço muitos esportes. Mas por enquanto estou fazendo só natação mesmo.” (FALA DO LUCAS, DIÁRIO DE CAMPO, 2017)

A disciplina de ciências era ministrada por outra professora. Embora ele também fosse participativo, essa professora não dava muito espaço para os alunos participarem ou fazerem questionamentos. Mas conseguimos perceber que ele se interessava bastante por assuntos relacionados à natureza e aos animais, pois ficava muito atento durante as explicações da professora.

Nas demais disciplinas, como história e geografia, ele era muito questionador. Quando a professora pedia para desenhar algo relacionado ao tema da aula, ele ficava animado, se apressava em pegar seus lápis de cor. Observamos que pensava muito antes de começar a colocar no papel os primeiros traços do que iria produzir, levantava várias vezes para mostrar à professora o que estava desenhando, mostrava e conversava com o colega ao lado. Seus desenhos eram bem coloridos.

Em relação a alguns traços presentes em Lucas, como a capacidade de questionamentos e a curiosidade, conforme Neves-Pereira (2007) são características identificadas em pessoas com indicadores de alto desempenho criativo. Acreditamos que ambas estão interligadas, pois a curiosidade leva ao questionamento daquilo que nos desperta interesse, que queremos conhecer ou entender.

Certo dia, a professora estava trabalhando o conceito de bairro e como atividade final pediu para que os alunos representassem o bairro onde vivem em forma de desenho e que depois fossem à frente para mostrar o que fizeram aos demais alunos. Quando foi a vez do Lucas, ele aparentou estar envergonhado, como a maioria dos seus colegas, talvez fosse a nossa presença em sala, mas aos poucos ele foi mostrando seu desenho, detalhe por detalhe. Sua arte era bem viva e ele pareceu muito detalhista. A maioria dos outros desenhos, embora fossem bem coloridos, apresentavam os mesmos traços padronizados que se repetiam, por exemplo, o modelo da casa que a maioria de nós aprendeu quando crianças, porém outras crianças usavam da criatividade e imaginação para dar outras formas e características aos seus desenhos, como era o caso de Lucas. 
O que nos chamou muita atenção foi o seu comportamento durante as aulas de artes. Houve uma aula em especial, que a professora os levou para a biblioteca. Lá todos ficaram encantados com os livros de histórias. O menino pegou um livro e começou a folheá-lo, em seguida começou a ler a história em voz alta, era uma história bem divertida que falava dos dragões, todos os colegas que estavam na mesma mesa que ele, escutavam atentamente a história. Possuía uma boa leitura em relação à maioria dos seus colegas de classe; enquanto lia a história, observamos que produzia os sons dos animais, mudava o tom de voz de acordo com os personagens, sempre sorrindo e brincando com aspectos da história que achava interessante. Analisando essa situação, percebemos que Lucas demonstrou ter um senso de humor bem desenvolvido para sua idade, pois deu vida à história utilizando-se de sons e brincadeiras com os personagens, fazendo com que seus colegas se divertissem. Para Martins e Chacon (2016b), o senso de humor é um dos indicadores do pensamento criativo.

\section{b) Enriquecimento Curricular}

Nos dias atuais, a sociedade nos apresenta informações que mudam constantemente, cabendo à escola o papel de atualizar, compreender e disseminar determinadas informações, colocando em prática as ações necessárias. Porém, nem sempre a escola consegue desempenhar adequadamente o seu papel. Alencar, Braga e Marinho (2016) apontam que vem diminuindo o espaço para a expressão da criatividade nas escolas brasileiras, enfatizando a necessidade de reformulações estruturais no sistema educacional brasileiro.

Conforme a Resolução CNE/CEB nº. 02/2001, artigo $8^{\circ}$ inciso IX as escolas da rede regular de ensino precisam estruturar tanto os currículos das classes comuns quanto das salas de recurso com

“[...] atividades que favoreçam, ao aluno que apresente [indicadores de] altas habilidades/superdotação, o aprofundamento e enriquecimento de aspectos curriculares, mediante desafios suplementares nas classes comuns, em sala de recursos ou em outros espaços definidos pelos sistemas de ensino no que tange o Artigo 24, V, “c”, da Lei 9.394/96” (BRASIL, 2001, p. 3).

Entretanto, Neves-Pereira (2007) aponta que em algumas escolas conseguimos encontrar um trabalho com atividades que favoreçam o desenvolvimento das capacidades criativas dos sujeitos; porém, a maioria das escolas impõe um currículo que suprime o pleno desenvolvimento dessas competências, pois enfatiza as atividades de memorização e reprodução de conhecimentos.

Levando em consideração a escassez de atividades diferenciadas na maioria dos currículos escolares brasileiros, Renzulli (2014) nos apresenta o Modelo de Enriquecimento para toda a Escola (SEM) ${ }^{4}$, que objetiva a introdução de recursos e apoio para o currículo dos professores da rede regular de ensino contribuindo para

4 School Enrichment Model. 
o enriquecimento da aprendizagem de toda a escola. É importante destacar que o enriquecimento é uma maneira de propiciar múltiplas experiências de aprendizagem enriquecedoras e prazerosas, que alimentem e estimulem o potencial de todos os alunos (VIRGOLIM, 2012; RENZULLI, 2014).

O sistema de enriquecimento (SEM) foi criado com base na concepção dos Três Anéis: habilidade acima da média, envolvimento com a tarefa e criatividade, onde os indivíduos que conseguem manifestar traços da interação entre os Três Anéis necessitam de oportunidades educacionais que desenvolvam suas habilidades e que normalmente não são viabilizadas no ensino regular. (RENZULLI; REIS, 1997; RENZULLI, 2014).

Cupertino (2008) afirma que enriquecimento curricular é a oportunização do currículo educacional através do oferecimento de conteúdos abrangentes e diversas experiências de aprendizagem para os alunos, sendo capaz de atender um público com necessidades distintas "[...] possibilitando a ampliação do desenvolvimento pessoal e oportunizando desafios compatíveis com suas habilidades" (VIRGOLIM, 2012, p. 103).

O ambiente escolar no qual o indivíduo está incluído possui um relevante papel social, segundo Stein (1974 apud ALENCAR; BRAGA; MARINHO, 2016 p. 26): "Estimular a criatividade envolve não apenas estimular o indivíduo, mas também afetar o seu ambiente social e as pessoas que nele vivem". Acreditamos que a partir do momento que afetamos de maneira positiva o ambiente social, as pessoas que estão ali se abrem para novos conhecimentos, começam a olhar para o trabalho criativo de outra forma, e a valorizá-lo, de modo que nossos estudantes terão mais oportunidades de enriquecimento criativo em seu cotidiano escolar e social.

Nossas observações em sala de aula revelaram o predomínio de atividades repetitivas e pautadas na reprodução. Como o nosso foco de pesquisa é o potencial criativo, buscamos elaborar uma situação de aprendizagem que, conforme Renzulli (2014, p. 543) envolvesse de maneira prazerosa o "uso de informações e habilidades de pensamento [...]". Sendo assim, planejamos e apresentamos à professora, uma proposta de intervenção com base nos interesses e necessidades da turma. Com o seu consentimento, oferecemos uma atividade de enriquecimento visando conhecer e estimular o potencial criativo tanto do aluno observado quanto dos seus colegas de classe, além de despertar na professora regente, o interesse por investir em atividades diferenciadas para sua prática docente.

Durante a realização da atividade de intervenção, observamos que alguns alunos estavam tímidos e dispersos, mas aos poucos, foram participando. A princípio, o aluno investigado pareceu um pouco quieto e envergonhado, mas em vários momentos da história, ele aparecia e se expressava, deixando evidente a sua atenção à atividade.

Alguns alunos não participaram ativamente, outros, participaram em determinados momentos, em especial quando eram convidados a falar, e outros ainda, participaram integralmente. Acreditamos que tenham ficados intimidados 
com a atividade, visto que não estão acostumados a participar de atividades lúdicas e diversificadas no contexto de sala de aula, conforme observado. Martins e Chacon (2016a) afirmam que todos os alunos, inclusive os que possuem indicadores de AH/ $\mathrm{SD}$, se passarem muito tempo realizando atividades repetitivas, em um ambiente que seja pouco desafiador, acabam se desmotivando, não tendo estímulos ou interesses por realizar outras atividades, e assim não conseguem desenvolver suas potencialidades ou têm dificuldades de ir além do que é proposto a eles. Acredita-se que pode ter sido o que aconteceu com alguns dos alunos, visto que crianças desta faixa etária costumam ser inventivas e imaginativas.

É interessante destacar que, embora a maioria dos desenhos não fosse do conto de fadas da Cinderela, as crianças davam um jeito criativo de incluí-los na história, dando a eles até mais de um papel dentro da mesma. Como mostra os exemplos a seguir:

Quadro 1 - Exemplos de como os alunos incluíam as imagens na história

\begin{tabular}{|c|l|}
\hline IMAGEM DO CARTÃO & \multicolumn{1}{c|}{ FALA DOS ALUNOS } \\
\hline Dragão & "tentou matar a Cinderela" \\
\hline Aranha & "a aranha morde, joga teia e picou a Cinderela" \\
\hline Frozen & "uma Princesa pois era amiga da Cinderela" \\
\hline Árvore & $\begin{array}{l}\text { "que tinha na Casa da Cinderela" } \\
\text { "foi nessa árvore que a Cinderela pegou e comeu uma } \\
\text { maçã e desmaiou" }\end{array}$ \\
\hline Super-Homem & $\begin{array}{l}\text { "era apaixonado pela Cinderela, então a salvou, mas } \\
\text { matou o Príncipe" }\end{array}$ \\
\hline
\end{tabular}

Fonte: Elaboração própria.

Em determinados momentos, os alunos retomavam características da história da Cinderela, em outros alimentavam a história com traços de outras histórias infantis. Por exemplo, uma criança tira um cartão que contém a imagem de uma árvore, em seguida outra narra que "a Cinderela comeu a maçã dessa árvore e desmaiou, pois a bruxa tinha colocado um veneno na maçã".

Renzulli (2014) defende a importância das atividades que envolvem o desenvolvimento da criatividade e possibilitam que as crianças trabalhem em problemas de relevância pessoal, podendo realizar variadas atividades investigativas. Porém, analisando o exemplo acima, vimos claramente que alguns alunos ainda se prendem a outras histórias. Embora o fato de unir histórias distintas possa ser considerado algo criativo, eles retornam para ideias que foram construídas por outras pessoas, sem que produzam um novo problema ou solução para o que thes foi apresentado. Talvez isso tenha ocorrido pela falta de exercícios e oportunidades que direcionem para uma prática investigativa e criativa.

Chegando ao final da história, uma criança pegou um cartão com a imagem do super-homem; Lucas disse que o super-homem ia salvar a Cinderela e outra 
criança acrescentou que o super-homem era apaixonado por ela e por isso a salvou, mas acabou matando o Príncipe para pode ficar com a Cinderela. Esse foi um momento bem interessante e divertido, pois, quando paramos para analisar, o super-homem é um personagem de outro contexto, cuja função é ser um herói que salva as pessoas e derrota os vilões, mas aqui ele se tornou um herói apenas para sua amada, pois acabou matando o Príncipe.

Ressalta-se que os alunos, no início da atividade, pareciam dispersos e pouco envolvidos, mas, ao longo da história, a maioria mostrou-se bastante participativa e motivada. Talvez este comportamento inicial fosse devido à falta de compreensão da proposta acompanhada de certa timidez, o que pode estar relacionado à escassez de atividades dessa natureza; por outro lado, pode ser consequência do estranhamento da presença de pessoas diferentes em sala de aula, sobretudo, com uma filmadora.

Embora a história tenha tido personagens em comum, as crianças foram criativas, mostrando-se capazes de dar um enredo diferente a ela, cheio de magia, de maneira a promover um novo desfecho para a história. É importante destacarmos a relevância do trabalho com contação e criação de histórias pelas próprias crianças, uma importante atividade de enriquecimento que estimula a criatividade, pois, conforme apresenta Marques (2015), elas estarão não só trabalhando a linguagem, mas também potencializando a capacidade de inventar histórias ricas e fascinantes, pois "[...] quando existe fantasia e imaginação, o ambiente em sala de aula ganha uma nova roupagem" (ALENCAR, 2016, p. 19).

No segundo momento, entregamos folhas de papel sulfite para os alunos e pedimos para que escrevessem ou desenhassem o que mais gostaram da história que construíram junto com seus colegas. Todos os alunos participaram mais ativamente desta atividade que da realizada anteriormente, mas a maioria ficou um pouco envergonhada na hora que pedimos para dizer aos colegas o que haviam desenhado.

Em relação ao Lucas, reparamos que estava bem envolvido com a produção do seu desenho, pensava em cada detalhe antes de colocar no papel, às vezes conversava com o colega ao lado, mostrando e falando sobre o seu desenho.

Considerando-se a necessidade de propiciar atividades educacionais que incentivem o desenvolvimento das $\mathrm{AH} / \mathrm{SD}$, e em especial, do potencial criativo, destacamos o Modelo Triádico de Enriquecimento, proposto por Renzulli, que é construído através das seguintes atividades: Atividades Exploratórias Gerais (Tipo I); Atividades de Treinamento em Grupo (Tipo II) e Investigações de Problemas Reais, Individuais ou em Pequenos Grupos (Tipo III), onde cada uma dessas atividades possuem objetivos diferentes (RENZULLI, 2014).

O enriquecimento do tipo I (atividades exploratórias gerais) tem como objetivo possibilitar aos alunos uma gama de disciplinas, hobbies, temas, locais e eventos que na maioria das vezes não estão inseridos no currículo do ensino regular, podendo ser viabilizados a grupos em geral ou a alunos que demonstram curiosidade em alguma área (RENZULLI, 2014). 
O enriquecimento do tipo II (atividades de treinamento em grupo) é caracterizado por motivar a participação em grupo, fornecendo materiais instrucionais que promovam "[...] o desenvolvimento de processos de pensamento e sentimento" (RENZULLI, 2014, p. 546). Essas atividades se apresentam de maneira geral ou específica. De maneira geral, em alguns casos, são viabilizadas para grupos de alunos ou em programas de enriquecimento, incluindo: desenvolvimento criativo e solução de problemas. E, de forma específica, busca-se instruir o aluno em uma área de interesse selecionada pelo mesmo (RENZULLI, 2014).

O enriquecimento do tipo III (atividades de investigações de problemas reais, individuais ou em pequenos grupos) são atividades que possibilitam aos alunos o papel de investigador real, onde os mesmos se comprometem a procurar e conhecer profundamente determinada área ou conhecimento (RENZULLI, 2014).

Embora essa delimitação entre os tipos não seja tão explícita durante as ações de enriquecimento, as atividades dos Tipos II e III tendem a ser desenvolvidas mais frequentemente, em salas de recursos ou centros/núcleos especializados, enquanto que as atividades do Tipo I, como a que desenvolvemos com a turma, são totalmente passíveis de serem realizadas no próprio espaço de sala de aula regular, beneficiando a todos os alunos. Por isso, atividades dessa natureza em sala de aula são tão importantes para o desenvolvimento de todos os alunos. Nesse sentido, Panzeri (2006, p. 265) destaca a importância do enriquecimento curricular com base em três objetivos:

"[...] criar um ambiente de aprendizagem mais adequado às características do aluno; garantir o domínio do currículo básico para a etapa/ano escolar; e [garantir] atividades que visem o desenvolvimento das capacidades e interesses do estudante."

A atividade de intervenção desenvolvida com os alunos visou alimentar o espaço da sala de aula de maneira lúdica, onde pudemos conhecer um pouco as capacidades de cada criança e o que desperta atenção e curiosidade. A partir da atividade realizada, notamos que a maioria se encanta por histórias de contos de fadas, e ficamos pensando: "por que não trabalhar com esse tipo de atividade, envolvendo outros temas ou disciplinas, visando também o desenvolvimento da criatividade?”. É uma importante reflexão que todos os educadores precisam se questionar, compreendendo as necessidades e competências de seus alunos.

Alencar, Braga e Marinho (2016) afirmam que a educação brasileira tem um grande desafio: pensar e planejar recursos que proporcionem ao aluno um contínuo, rico e prazeroso processo de aprendizagem, tendo como elemento principal o desenvolvimento da criatividade.

\section{c) Concepçóes Teóricas da Professora}

A professora relata que participou de várias formações continuadas, porém, em nenhuma delas foi abordado o tema das AH/SD. Acredita que uma criança com $\mathrm{AH} / \mathrm{SD}$ " [...] é aquela que se destaca em meio aos demais, na maneira que pesquisa, 
lê, escreve e realiza suas atividades" (FALA DA PROFESSORA, DIÁRIO DE CAMPO, 2017). Nota-se que sua concepção é baseada no senso comum, pois desconhece a necessária presença da criatividade, bem como do envolvimento com a tarefa, conforme a definição legalmente assumida ${ }^{5}$, comprovando que é preciso investir na formação docente sobre este tema.

Neves-Pereira (2007) relata que os programas de formação continuada para os profissionais da educação têm grande responsabilidade de abordarem esse contexto, isso porque, na maioria das vezes, os professores não foram preparados para o ensino que desenvolva o potencial criativo. Desta forma, os professores acabam tendo dificuldades em propiciar uma prática de ensino criativa e transformadora, pois as informações que possuem são insuficientes em relação à importância do desenvolvimento do potencial criativo para o campo das altas habilidades/superdotação.

A professora regente concebe que a criatividade é uma característica presente em determinadas pessoas que, quando realizam uma atividade, vão além do que propomos para elas, pois têm em seu interior, algo que precisam expressar.

Com base nessa opinião, analisamos que a professora também possui um conceito de criatividade equivocado, pois desconhece que esta é uma característica inerente a todos os indivíduos. Segundo Neves-Pereira (2007, p. 16), "[...] a criatividade é um fenômeno presente, de modo potencial, em todos os seres humanos", ou seja, todos são dotados de potencial criativo sendo preciso um ambiente enriquecedor com atividades que estimulam o desenvolvimento desse potencial. Daí a importância da imaginação, da resolução de problemas, do questionamento, da inovação e da inventividade no contexto escolar.

\section{d) Prática Pedagógica}

Em relação a sua prática diária, a professora relata que percebe que alguns alunos possuem dificuldades, então ela procura trazer atividades diversificadas para a sala de aula, como dinâmicas, atividades lúdicas, jogos, cantigas visando facilitar e dinamizar as suas atividades. Trabalha bastante a questão da oralidade para que os alunos construam conhecimentos, aprendam e tenham confiança na aula e na hora de falar em público, pois, mesmo estando entre os colegas de sala, muitos são tímidos na hora de falar e não conseguem se expressar. A partir desse relato, notase que a preocupação da professora está mais centrada nas dificuldades que nas potencialidades dos estudantes.

Em sala de aula, observamos que a professora regente possui uma prática ainda marcada por alguns traços tradicionalistas de ensino, utilizava-se muito do quadro negro e de atividades xerocadas. Embora trouxesse para a sala de aula materiais diferentes para trabalhar os conteúdos com os alunos, não se aprofundava em explorar determinado recurso, como acontecia quando levava músicas diferentes

5 Política Nacional de Educação Especial na perspectiva da Educação Inclusiva (BRASIL, 2008).

Signos, Lajeado, ano 40, n. 1, p. 98-120, 2019. ISSN 1983-0378 
para cantar com as crianças; porém, seria necessário explorar tais músicas como instrumentos para criação de ideias, de histórias, no trabalho com os gestos e movimentos e não somente no desenvolvimento da oralidade.

Como um aspecto positivo a ser ressaltado, a professora sempre cantava uma ou duas músicas com os alunos no início das aulas. Era nítido que eles gostavam de cantar e que a professora vinha trabalhando essa prática há algum tempo, pois as músicas não eram as mesmas e sabiam fielmente a letra e o ritmo de todas, o que demonstra a presença de ludicidade na rotina.

Durante o tempo de observação, a professora nos pareceu ser bem acolhedora e comunicativa com os alunos, entretanto, algumas vezes, sentimos que ela não conseguia lidar com as necessidades de alguns alunos, inclusive com as do Lucas. Notamos isso, na maneira como se relacionava com eles durante a explicação e execução de algumas atividades. Observamos que um dos alunos apresentava um comportamento bem diferente de seus colegas, sendo mais desatento e disperso durante a aula e quando começava a fazer uma atividade, não a terminava, conversava muito pouco com seus colegas e quase não respondia o que a professora perguntava a ele. Por isso, não enxergamos uma prática diferenciada com o mesmo, embora a professora o acompanhasse e se interessasse por ele, não houve uma atividade que ela conseguisse envolvê-lo na aula e, no tempo que dedicava tentando conversar e explicar as atividades para ele, os demais alunos ficavam realizando suas atividades sem um acompanhamento necessário, o que parece sugerir a relevância de maior suporte à docente por parte do sistema educacional, seja por meio de ações formativas, seja em relação à distribuição do número de alunos por professor.

Costumava trazer para as aulas, folhas com cantigas de roda, poesias, parlendas, músicas, jogos de caça palavras, quebra-cabeças, material dourado, dentre outros matérias didáticos. Porém, quando trabalhava com algum desses materiais, não aprofundava o estudo, por exemplo, houve um dia em que trouxe uma cantiga de roda, fez a leitura, releu com os alunos, ensinou a melodia, cantou com eles, mas não explicou o que são as cantigas de rodas, qual a sua origem; pois assim ela estaria ampliando o conhecimento cultural de seus alunos de forma significativa. Também seria possível solicitar produções diversas (textuais, musicais, ilustrativas, lúdicas), individuais ou coletivas, a partir da cantiga apresentada.

A professora regente levava para a sala de aula diversos materiais, como os citados anteriormente, para diversificar suas aulas, o que também contribuía para torná-las mais prazerosas, porém, concebemos que o trabalho com esses materiais não é suficiente para o desenvolvimento da criatividade. Há uma necessidade de atividades mais abrangentes que estimulem e explorem o potencial criativo de todos os alunos, permitindo-os usar a imaginação, investigar e criar.

As crianças precisam de um ambiente que alimente o seu potencial criativo com experiências ricas, significativas e emancipatórias, materiais diversos ao seu dispor, experiências sensoriais com o outro e com o ambiente, liberdade para pensar e criar (LOWENFELD; BRIT'TAIN, 1970). 
Alencar (2001) afirma que o ambiente de ensino é importante no processo de desenvolvimento do potencial criador. Sendo assim, é necessário adotar práticas de ensino que favoreçam a expressão criadora, contrapondo à memorização de conteúdos que inibe a criatividade. Levando em consideração a prática da professora observada, acreditamos na importância de que os educadores conheçam e concebam a criatividade em sua complexidade para que as práticas de ensino sejam repensadas em benefício do desenvolvimento do potencial criativo, pois é necessário que os discentes experienciem momentos em que possam pensar sozinhos e em conjunto, em que testem suas ideias, manifestem a curiosidade e a imaginação, colocando em prática suas habilidades intelectuais e criativas (ALENCAR, 2001; MARTINS, 2013).

$\mathrm{Na}$ sua prática com Lucas, notamos que a professora regente era bastante atenciosa. Conversava muito com ele, deixando espaço para que expressasse sua opinião durante as aulas. Em relação a um trabalho diferenciado, ela sempre levava um jogo matemático ou de raciocínio lógico para trabalhar tanto com os outros alunos quanto o aluno em questão, pois este tinha certa dificuldade nessa área. Um dia, a professora passou no quadro algumas operações de soma e subtração que envolviam raciocínio rápido. Lucas parecia meio inquieto, mas realizava a atividade com atenção, a professora foi à mesa dele, levou várias tampinhas de garrafa e explicou como ele poderia usar as tampinhas para resolver as operações. Ele permanecia atento à explicação da professora e, logo em seguida, já estava realizando a atividade de maneira autônoma.

“-Professora, já entendi, pode ir ajudar meus colegas. É fácil e já sei fazer sozinho.” (FALA DO LUCAS, DIÁRIO DE CAMPO, 2017)

Para Neves-Pereira (2007), o professor é um importante mediador do processo de aprendizagem, porém, a grande maioria não reconhece a existência do potencial criativo de seus alunos. Acreditamos que, primeiramente, o professor precisa se perceber como um importante agente no processo de aprendizagem e de desenvolvimento das habilidades e em seguida, entender que a promoção da criatividade é uma ação complexa, que envolve não só o domínio de suas capacidades criatividades, mas também a maneira como pode potencializar o desenvolvimento das capacidades criativas de seus alunos.

A professora buscou, em vários momentos, trabalhar de maneira diferente com Lucas, mas acredita-se que os recursos utilizados não são suficientes para o trabalho com a criatividade.

A falta de atividades diversificadas e compatíveis e com o nível de desenvolvimento do indivíduo pode fazer com que o mesmo perca o interesse e motivação pela aprendizagem escolar, por isso, é extremamente importante que o professor conheça seus alunos, tanto as necessidades quanto as capacidades, considerando os conhecimentos que o mesmo já possui, tendo estes como ponto de partida para o planejamento de sua prática. (BENITO, 2000; MARTINS; CHACON, 2016b). 
Além de conhecer os seus alunos e valorizar as habilidades dos mesmos, é importante que o professor desperte neles a consciência do potencial criativo que cada um possui, assim os próprios alunos buscarão se conhecer mais intimamente, tirando o melhor proveito de seu potencial (ALENCAR; BRAGA; MARINHO, 2016).

Quando questionada em relação ao trabalho de enriquecimento que realizamos com os alunos, a professora considera que toda atividade que estimule a criatividade é válida em sala de aula.

"Achei bem interessante o modo como a dramatização da história foi trabalhada, pois as próprias crianças foram estimuladas a pensar em um momento novo na história. Cada uma foi capaz de pensar em uma ideia, e juntas construíram uma nova história, diferente das já existentes" (PROFESSORA REGENTE, DIÁRIO DE CAMPO, 2017).

Observando o depoimento acima, acreditamos que a professora reconheceu a importância de se trabalhar com atividades desse porte. Pois viu o quão prazeroso a mesma é e o quanto os alunos se envolveram com a atividade, participando e expressando suas capacidades em conjunto de maneira que um foi capaz de contribuir com o pensamento do outro; mas destaca-se que essas capacidades precisam ser trabalhadas constantemente.

A professora disse que pensa em desenvolver atividades de enriquecimento com seus alunos, semelhantes ao nosso trabalho, pois considera que são práticas importantes para o desenvolvimento dos estudantes. Porém, ela ressalta que é necessário que a instituição de ensino apoie os professores e disponibilize materiais diversificados e adequados. Nesse diálogo, a professora deixa bem claro a necessidade de formação docente: "é preciso conversar mais com os professores sobre este tema pois a maioria dos professores não conhecem muito dessa área," (FALA DA PROFESSORA, DIÁRIO DE CAMPO, 2017), pois considera que a maioria dos professores não sabia da existência de alunos com indicadores de $\mathrm{AH} /$ $\mathrm{SD}$ na escola, e que é preciso ter mais diálogo entre a coordenação pedagógica e os professores.

Destacamos que muitos professores pensam e buscam maneiras de inovar sua prática pedagógica, como é o caso da professora de nosso estudo, porém nem sempre os mesmos encontram suporte e apoio necessário para tal feito. É um problema que precisa ser superado, pois, segundo Alencar, Braga e Marinho (2016) na maioria das vezes o professor acaba se desanimando na busca por uma prática que desenvolva a criatividade se o mesmo não tiver assistência e apoio necessários dos gestores e coordenadores pedagógicos.

\section{Consideraçóes Finais}

Considerando os resultados obtidos no decorrer da pesquisa, identificamos que o aluno observado possui alguns indicadores de $\mathrm{AH} / \mathrm{SD}$ que precisam ser desenvolvidos e potencializados. Porém, descobrimos que a professora regente 
tem uma concepção marcada pelo senso comum, acreditando que apenas alguns alunos são capazes de se destacar em certas atividades e desenvolver a criatividade. Sabemos que a maneira como concebemos algo influencia no nosso modo de trabalho, por isso, embora a professora fosse dedicada e atenciosa com seus alunos, principalmente com Lucas, não conseguimos identificar atividades voltadas para o desenvolvimento da criatividade dos alunos. Notamos que sua prática era mais voltada para sanar as dificuldades do que desenvolver as potencialidades dos estudantes.

Considerando as práticas pedagógicas observadas em sala de aula, acreditamos que há muito a ser trabalhado nos programas de formação de professores, visando o reconhecimento das $\mathrm{AH} / \mathrm{SD}$, a necessidade de se investir em atividades de enriquecimento que favoreçam o florescimento e desenvolvimento de forma integral das capacidades dos sujeitos criativos. É preciso que os educadores se vejam como um sujeito dotado de responsabilidades no que tange a uma educação emancipadora e que o mesmo pode planejar seu currículo levando sempre em consideração a realidade de seus alunos.

A escola também tem o papel de viabilizar um ambiente cheio de oportunidades. Por isso, ressaltamos que é preciso que coordenação pedagógica e professores caminhem juntos, se apoiando, pensando e trabalhando em novas formas de envolver seus alunos no processo de uma aprendizagem criativa e significativa.

Em relação à atividade de intervenção realizada, consideramos que foi relevante para o nosso trabalho, pois a partir do momento que oportunizamos essa atividade de enriquecimento observamos que a maioria dos alunos ficou surpresa e curiosa pelo o que seria feito. Mostraram-se atentos, animados e envolvidos. O Lucas se mostrou bem participativo durante a atividade e criativo no momento do desenho e alguns alunos deixaram aflorar características que durante as aulas observadas não conseguiam demonstrar, como a atenção, boa memória, a forma como usavam e exploravam as cores, entre outros.

Acreditamos que para que o desenvolvimento integral do potencial criativo ocorra de maneira plena e satisfatória, todos os sujeitos envolvidos, precisam trabalhar em conjunto, pois o mundo no qual vivemos sofre tantas mudanças que somente um sujeito com uma mente criativa será capaz de acompanhar e se adaptar a elas, podendo vir a prestar contribuições significativas à sociedade.

\section{Referências}

ALENCAR, Eunice M.L. Soriano de. Criatividade e educação de superdotados. Petrópolis: Vozes, 2001.

ALENCAR, Eunice M. L. Soriano de; BRAGA, Nívea Pimenta. MARINHO, Claudio

Delamare. Como desenvolver o potencial criador: um guia para a liberação da criatividade em sala de aula. 12. ed. Petrópolis- RJ: Vozes, 2016. 
ANTIPOFF, Cecília Andrade; CAMPOS, Regina Helena de Freitas. Superdotação e seus mitos. Revista Semestral da Associação Brasileira de Psicologia Escolar e Educacional, SP. Vol. 14, n. 2, Jul/Dez de 2010 301-309.

BARDIN, Laurence. Análise de conteúdo. Tradução de Luís Antero Reto, Augusto Pinheiro. São Paulo: Edições 70, 2016.

BRASIL. Lei de Diretrizes e Bases da Educação Nacional: Lei no 9.394, de 20 de dezembro de 1996 - 8. ed. - Brasília: Câmara dos Deputados, Edições Câmara, 2013. 45 p.

. Resolução CNE/CEB nº. 02, de 11 de setembro de 2001. Institui Diretrizes Nacionais para a Educação Especial na Educação Básica. Disponível em: http://portal. mec.gov.br/cne/arquivos/pdf/CEB0201.pdf Acesso em 15 de outubro de 2018.

Política Nacional de Educação Especial na Perspectiva da Educação Inclusiva. Brasília: MEC/SEESP, 2008.

BENITO, Y. Definición, pautas de identificación y educación para padres y profesores. In: BENITO,Y. (Org.). Intervención e investigación psicoeducativas en alumnos superdotados. 2.ed. Salamanca: Amarú Ediciones, 2000. p.79-93.CARVALHO, R. E. Escola inclusiva: a reorganização do trabalho pedagógico. 6. ed. Porto Alegre: Mediação, 2014

CUPERTINO, Christina Menna Barreto. Educação dos diferentes no Brasil: o caso da superdotação. Anais do $1^{\circ}$ Congresso Internacional de Educação da Alta Inteligência, promovido pela Universidade da Provincia de Cuyo e pelo Instituto San Bernardo de Claraval. Mendoza, Argentina, ago. 1998.

CUPERTINO, Christina Menna Barreto. (org.). Um olhar para as altas habilidades: construindo caminhos/Secretaria da Educação. São Paulo: FDE, 2008.Disponível em: http://cape.edunet.sp.gov.br/cape_arquivos/Um_Olhar_Para_As_Altas_ habilidades_2\%C2\%B0_Edi $\%$ C3\%A7\%C3\%A3o.pdf Acesso em: 17 de novembro de 2018.

DALFOVO, Michael Samir; LANA, Rogério Adilson; SILVEIRA, Amélia. Métodos quantitativos e qualitativos: um resgate teórico. Revista Interdisciplinar Científica Aplicada, Blumenau, v.2, n.4, p.01-13, Sem II. 2008. Disponível em: https://www3.ufpe. $\mathrm{br} /$ moinhojuridico/images/ppgd/9.1b\%20metodos_quantitativos_e_qualitativos_um_ resgate_teorico.pdf Acesso em 28 de setembro de 2018.

DELOU, Cristina Maria Carvalho. Educação do aluno com altas habilidades/ superdotação: legislação e políticas educacionais para inclusão. In FLEITH, D. (org.). A Construção de Práticas Educacionais para Alunos com Altas Habilidades/ Superdotação. Brasília: MEC, 2007. p. 25-40 Disponível em: http://portal.mec.gov.br/ seesp/arquivos/pdf/altashab2.pdf Acesso em: 17 de fevereiro de 2019. 
DIEHL, Astor Antônio. Pesquisa em ciências sociais aplicadas: métodos e técnicas. São Paulo: Prentice Hall, 2004.

GAMA, Maria Clara Sodré S. Educação de superdotados: teoria e prática. São Paulo: E.P.U., 2006.

GIL, Antônio Carlos. Métodos e técnicas de pesquisa social. $6^{\mathrm{a}}$ ed. São Paulo: Atlas S.A, 2008.

LOWENFELD, Viktor; BRITTAN, Willian Lambert. A importância da atividade criadora na educação. In: LOWENFELD, Viktor; BRITTAN, Willian Lambert. Desenvolvimento da capacidade criadora. São Paulo: Mestre Jou, 1970. p.35-71.

MARQUES, Danitiele Maria C. Reconhecimento por meio de indicadores da precocidade do aluno na educação infantil. 2013. 159f. Dissertação (Mestrado em Educação Especial) - Programa de Pós-Graduação, Centro de Educação e Ciências Humanas, Universidade Federal de São Carlos, São Carlos, 2013.

MARTINS, Barbara Amaral. Alunos precoces com indicadores de altas habilidades / superdotação no ensino fundamental I: identificação e situações (des)favorecedoras em sala de aula. Dissertação (Mestrado em Educação) Programa de Pós-Graduação. Faculdade de Filosofia e Ciências da Universidade Estadual Paulista "Júlio de Mesquita Filho", Marília, 2013.

MARTINS, Bárbara Amaral. A aceleração da criança precoce em idade pré-escolar. Revista Diálogos e Perspectivas em Educação Especial, v.2, n.2, p. 115-130, Jul.Dez., 2015.

MARTINS, Bárbara Amaral. CHACON, Miguel Claudio Moriel. Crianças precoces com indicadores de altas habilidades/superdotação: as características que contrariam a imagem de aluno "ideal”. Educação Unisinos v. 20, n.1, p. 96-105, jan/abr 2016a.

MARTINS, Bárbara Amaral. CHACON, Miguel Claudio Moriel. Características de altas habilidades/superdotação em aluno precoce: um estudo de caso. Revista Brasileira Educação Especial, Marília, v. 22, n. 2, p. 189-202, Abr.-Jun. 2016b.

NAKANO, Tatiana C. WECHSLER, Solange M. 2017. Identificação e avaliação do talento criativo. In: FLEITH. Denise S. Desenvolvimento de talentos e altas habilidades: orientação a pais e professores. Porto Alegre, Artmed, p. 87-98

NEVES-PEREIRA, Mônica Souza. Estratégias de promoção de criatividade. In: FLEITH, Denise de Souza. A construção de práticas educacionais para alunos com altas habilidades/superdotação. vol.2 Brasília, DF: Ministério da Educação, Secretaria de Educação Especial, 2007.

PANZERI, M.V. Los niños talentosos y superdotados una respuesta educativa: “enriquecimiento em la escuela común”. In: FREITAS, S.N. (Org.). Educação e altas 
habilidades/superdotação: a ousadia de rever conceitos e práticas. Santa Maria: Ed. da UFSM, 2006. p.257-277.

RENZULLI, Joseph S. O Que é Esta Coisa Chamada Superdotação, e Como a Desenvolvemos? Uma retrospectiva de vinte e cinco anos. Educação, vol. XXVII, núm. 52, p. 75-13, jan-abr, 2004. Pontifícia Universidade Católica do Rio Grande do Sul Porto Alegre, Brasil.

RENZULLI, Joseph. S. The Three-Ring conception of giftedness. A developmental model for promoting creative productivity. In: R. J. STERNBERG \& J. E. DAVIDSON (Eds.), Conceptions of giftedness (2nd ed., pp.246-279). New York: Cambridge University Press. 2005.

RENZULLI, Joseph. Modelo de enriquecimento para toda a escola: um plano abrangente para o desenvolvimento de talentos e superdotação. (Tradução: Susana Graciela Pérez Barrera Pérez). Revista Educação Especial. V.27, n.50, p.539-562, set/dez.2014, Santa Maria.

RENZULLI, Joseph; REIS, Sally. M. The schoolwide enrichment model: A how-to guide for educational excellence (2nd ed.). Mansfield Center, CT: Creative Learning Press, 1997.

TORRANCE, Ellis Paul. Criatividade: medidas, testes e avaliações. São Paulo: IBRASA, 1976. Revista Semestral da Associação Brasileira de Psicologia Escolar e Educacional, SP. Vol. 14, nº 2, 293 p. Julho/Dezembro de 2010.

VIRGOLIM, Ângela M. R. A contribuição dos instrumentos de investigação de Joseph Renzulli para a identificação de estudantes com altas habilidades/ superdotação. Anais do IV Encontro Nacional do CONBRASD. I Congresso Internacional sobre altas habilidades/superdotação. IV Seminário sobre altas habilidades/superdotação da ufpr. Centro de Convenções de Curitiba - Curitiba - Paraná, 13 a 15 de setembro de 2010.

VIRGOLIM, Ângela M. R. A educação de alunos com altas habilidades/superdotação em uma perspectiva inclusiva. In MOREIRA, Laura Ceretta; STOLTZ, Tania (coords.). Altas Habilidades/superdotação, talento, dotação e educação. Curitiba: Juruá, 2012. p. 95-112.

WECHSLER, Solange M.; NAKANO, Tatiana de Cassia. Criatividade: encontrando soluções para desafios educacionais. In WECHSLER, Solange M.; TREVISAN, Vera Lúcia de Souza. Criatividade e aprendizagem: caminhos e descobertas em perspectivas internacionais. São Paulo, SP; Editora Loyola, 2011, p. 11-31. 